'llu. Revista de Ciencias de las Religiones

ISSN: $1135-4712$

http://dx.doi.org/10.5209/ILUR.61033

\title{
Estudios mudéjares en el siglo veintiuno: una bibliografía seleccionada
}

Mònica Colominas Aparicio ${ }^{1}$

\section{[en] Mudejar Studies in the Twenty-first Century: A Selected Bibliography}

\author{
Esquema:
}

1. Introducción

2. Los estudios mudéjares en el siglo XXI

2.1. Trabajos sobre las relaciones entre comunidades religiosas en la península ibérica

2.2. Trabajos sobre comunidades mudéjares

2.2.1. Trabajos de síntesis

2.2.2. Trabajos sobre los mudéjares de los diferentes reinos peninsulares

2.2.3. Volúmenes editados

2.2.4. Publicaciones sobre fuentes documentales relativas a mudéjares

3. Temas de investigación dentro de los estudios mudéjares

3.1. Organización de las comunidades o aljamas

3.1.1. Familias, élites y redes de poder

3.1.2. Movilidad

3.1.3. Jurisprudencia islámica

3.2. Identidad religiosa de los mudéjares y práctica del islam

3.2.1. Identidad religiosa mudéjar

3.2.2. Corán, literatura religiosa y predicación

3.2.3. Polémica interreligiosa y conversión

3.3. Transmisión del conocimiento: lenguaje, producción manuscrita y codicología

3.4. Minorías dentro de las minorías: mujeres y esclavos

4. El estado de la cuestión sobre los estudios mudéjares

Anexo: trabajos sobre mudejarismo en el arte y la arquitectura

\section{Introducción ${ }^{2}$}

La presencia del islam y de musulmanes ocupa un lugar destacado en el actual debate sobre la integración de minorías religiosas en países europeos y occidentales que

\footnotetext{
1 Max Planck Institute for the History of Science, Berlín (Alemania).

Correo electrónico: mcolominasaparicio@mpiwg-berlin.mpg.de

2 Quiero agradecer los comentarios críticos y las sugerencias a las versiones previas de este artículo de Gerard Wiegers (Universidad de Ámsterdam) y Teresa Soto González (Universidad de Salamanca).
} 
se definen como seculares pero que arraigan en un pasado predominantemente cristiano, así como también es objeto de reflexión entre los musulmanes en estas regiones y en los países de mayoría musulmana. Esta presencia no es completamente nueva, sino que hay de ella importantes precedentes históricos como el de los mudéjares que habitaron en los territorios que hoy conforman España y Portugal. Mudéjar (del árabe dajn que significa 'tratado') es el término por el que se conoce a los musulmanes que permanecieron en los emergentes reinos cristianos tras la rendición de los territorios de al-Andalus y que pudieron practicar el islam a cambio del pago de unos impuestos extraordinarios fijados por las capitulaciones o tratados. Son incontables los trabajos y las publicaciones que se han dedicado al estudio de estos grupos, que se rigieron por un ordenamiento jurídico y por unas estructuras sociales semiautónomas, y que compitieron directamente con los cristianos y con las minorías judías por la distribución de la riqueza y por la ascensión social en los territorios.

Ante la abundante producción, el presente Boletín Bibliográfico se centra en los estudios más recientes y toma el cambio de siglo como punto de partida. Se pretende ofrecer una visión general y sintética de la bibliografía sobre mudéjares que sea de utilidad al lector y que incluya las aportaciones más significativas y las líneas principales de las investigaciones durante este periodo. Es por ello que se sigue el criterio de representatividad y no de exhaustividad en la selección de la bibliografía comentada que trata sobre sus comunidades hasta los últimos edictos de conversión en el reino de Valencia de 1526. Aunque a menudo los trabajos sobre mudéjares y conversos al cristianismo, o moriscos, están fuertemente relacionados entre sí, las menciones a trabajos sobre moriscos se limitan por brevedad a publicaciones puntuales que son de particular relevancia. El texto se divide en tres secciones principales: primero se abordan de forma general los estudios sobre mudéjares y se tratan las publicaciones sobre relaciones entre musulmanes, cristianos y judíos en la península ibérica (2.1) y los trabajos sobre sus comunidades (2.2). En la sección numerada como (3) se tratan los temas con mayor presencia dentro de la literatura en los últimos años. La última sección (4) ofrece una recapitulación y algunas reflexiones sobre el estado de los estudios mudéjares junto con una selección de artículos que también se ocupan de analizar el estado del campo. Finalmente, debemos de hacer un apunte sobre mudejarismo, que es el término que generalmente se usa para hacer referencia a la arquitectura y al arte que se vincula con expresiones y prácticas culturales musulmanas fuera de los territorios musulmanes. La evaluación rigurosa de estas publicaciones que, cabe señalar, han sido particularmente abundantes, cae fuera de los intereses principales de la revista en la que se incluye esta bibliografía, así como de mi campo de especialización. No obstante, se ha considerado necesario ofrecer al lector interesado una relación de recientes monográficos y volúmenes editados sobre mudejarismo que se incluye en el Anexo final.

Antes de abordar la tarea que aquí nos ocupa parece adecuado ofrecer un breve repaso por la evolución de los estudios mudéjares, que se acompaña al final de una bibliografía selecta en la que no se incluyen publicaciones en lenguas no europeas menos accesibles al público general de esta revista, tales como el árabe o el turco. El incipiente interés por las cuestiones relativas a las condiciones de vida y a la organización social de las comunidades mudéjares se aprecia ya en el siglo diecinueve (consúltese por ejemplo la importante publicación de Fernández y González, Francisco. Estado social y político de los mudéjares de Castilla. Madrid, 1866 así como también los volúmenes de De Circourt, Albert (comte). Histoire des mores 
mudejares et des morisques: ou des arabes d'Espagne sous la domination des chrétiens, 3 Vols. Paris: G.A. Dentu, 1846). Sin embargo, son sus descendientes moriscos forzados a convertirse al cristianismo, pero practicantes del islam en secreto hasta la expulsión final de sus comunidades entre 1609 y 1614, quienes reciben una mayor atención hasta la primera mitad del siglo veinte. Con todo aparecen en estos años obras destacadas como las de Francisco Macho y Ortega (Macho y Ortega, Francisco. "Condición social de los mudéjares aragoneses (siglo XV)." Memorias de la facultad de filosofía y letras de la Universidad de Zaragoza 1 (19221923): 137-231 y del mismo autor "Documentos relativos a la condición social y jurídica de los mudéjares aragoneses." Revista de ciencias jurídicas y sociales 5 (1922): 143-160 y 444-464); Isidro de las Cagigas (De las Cagigas, Isidro. Los mudéjares, 2 Vols. Madrid, 1948-1949); Miguel Gual Camarena (Gual Camarena, Miguel. "Mudéjares valencianos, aportaciones para su estudio." Saitabi 7 (1949): 165190); y Francisco A. Roca Traver (Roca Traver, Francisco A. Un siglo de vida mudéjar en la Valencia medieval (1238-1338). Zaragoza: Impr. "Heraldo de Aragón”, 1952).

Habrá que esperar hasta finales de los años sesenta para ver surgir los estudios mudéjares como subdisciplina dentro del campo dedicado a la península ibérica y al mundo Mediterráneo premodernos. En las escasas décadas que comprenden de los años setenta hasta finales de los años noventa del siglo pasado la disciplina evoluciona de forma no homogénea según los nuevos postulados y tendencias generales dentro de la academia que rompen con el positivismo y la modernidad. Lo hace de forma intensa y alcanzando importantes hitos para la disciplina, por lo que podemos referirnos a este periodo como periodo formativo. En él encontramos las siguientes publicaciones monográficas de interés ${ }^{3}$ :

— Ladero Quesada, Miguel Ángel. Los mudéjares de Castilla en tiempo de Isabel I. Valladolid: Instituto "Isabel la Católica" de Historia Eclesiástica, 1969.

- Burns, Robert I. Islam under the Crusaders: Colonial Survival in the ThirteenthCentury Kingdom of Valencia. Princeton, N.J.: Princeton University Press, 1973.

- Boswell, John. The Royal Treasure: Muslim Communities under the Crown of Aragon in the Fourteenth Century. New Haven: Yale University Press, 1977.

- Glick, Thomas. Islamic and Christian Spain in the Early Middle Ages. Princeton: Princeton University Press, 1979.

- García-Arenal, Mercedes-Leroy, Béatrice. Moros y judios en Navarra en la Baja Edad Media. Madrid: Hiperión, 1984.

- Ferrer i Mallol, Maria Teresa. Els sarraïns de la Corona Catalano-Aragonesa en el segle XIV: segregació i discriminació. Barcelona: Consell Superior d'Investigacions Científiques, 1987.

- Barceló Torres, María del Carmen. Minorías islámicas en el País Valenciano: historia y dialecto. [Valencia]: Universidad de Valencia, Secretariado de Publicaciones, Facultad de Filología, Instituto Hispano-Árabe de Cultura, 1984.

- Harvey, Leonard Patrick. Islamic Spain, 1250 to 1500. Chicago: University of Chicago Press, 1990.

3 Para facilitar la comprensión de la evolución y de cambios dentro de la disciplina se han ordenado aquí las publicaciones en orden cronológico. Las referencias bibliográficas en las secciones siguientes se presentan no obstante siguiendo el orden alfabético habitual. 
- Lourie, Elena. Crusade and Colonisation: Muslims, Christians, and Jews in Medieval Aragon. Aldershot [etc.]: Variorum, 1990.

- Guichard, Pierre. Les musulmans de Valence et la Reconquête (Xle-Xllle siècles)/ The Muslims of Valencia and the Reconquest (Eleventh-Thirteenth Centuries), 2 Vols. Damascus: Institut Français de Damas, 1990 y 1991.

- Meyerson, Mark. The Muslims of Valencia in the Age of Fernando and Isabel: Between Coexistence and Crusade. Berkeley, Los Angeles: University of California Press, 1991.

- Wiegers, Gerard Albert. Islamic Literature in Spanish and Aljamiado. Yça of Segovia (fl. 1450): His Antecedents \& Successors. Leiden [etc.]: E.J. Brill, 1994.

- Ledesma Rubio, María Luisa. Estudios sobre los mudéjares en Aragón. Teruel: Instituto de Estudios Turolenses, 1996.

- Nirenberg, David. Communities of Violence: Persecution of Minorities in the Middle Ages. Princeton: Princeton University Press, 1996.

\section{Los estudios mudéjares en el siglo XXI}

Los estudios dedicados a los mudéjares en el nuevo milenio parten de trabajos fundamentales como los mencionados y entrañan en muchos sentidos la continuación y la profundización de las líneas de investigación abiertas durante el siglo anterior y en particular durante el periodo formativo. El nivel de madurez alcanzado por la disciplina ha permitido no obstante la incorporación de nuevas perspectivas y el planteamiento de preguntas que se enmarcan dentro de las tendencias recientes en el campo de las humanidades y de las que se dará razón detallada más abajo. En particular, dentro de estas tendencias se aprecia un interés importante por el estudio de las minorías (religiosas, étnicas, sociales, de género, ...) y por los procesos de construcción de la identidad de sus miembros a partir de la interacción discursiva en situaciones de contacto en contextos específicos. Dentro del campo de estudio de la religión hay también interés por los discursos de la identidad y la fluidez del sujeto junto con una tendencia a privilegiar la práctica religiosa entendida como el resultado de procesos que fluyen de abajo arriba por encima de los enfoques en la normatividad concebida de arriba abajo. Aunque la incorporación de nuevos métodos y perspectivas depende en gran medida de la evolución y de la historia de cada disciplina particular, no se puede pasar por alto la incidencia de algunos fenómenos tales como la globalización en el fomento del trabajo interdisciplinario y de colaboración entre especialistas.

\subsection{Trabajos sobre las relaciones entre comunidades religiosas en la península ibérica}

Entre las publicaciones recientes que examinan las relaciones entre cristianos, musulmanes y judíos en la península ibérica dos merecen ser destacadas: una, el trabajo de María Rosa Menocal en 2002 (Menocal, María Rosa. The Ornament of the World: How Muslims, Jews, and Christians Created a Culture of Tolerance in Medieval Spain. Boston: Little, Brown and Company, 2002); la otra, la monografía a cargo de David Nirenberg (Nirenberg, David. Neighboring Faiths: Christianity, Islam, and Judaism in the Middle Ages and Today. Chicago, London: University of Chicago 
Press, 2014). Ambos autores articulan sus tesis en torno a la convivencia, o el término por el que generalmente se designa a la coexistencia de las tres comunidades dentro de los territorios peninsulares. Menocal entiende la convivencia como catalizador, como elemento estimulante para la difusión y el alto nivel de desarrollo intelectual que se alcanzó dentro de la sociedad omeya andalusí, mientras que Nirenberg parte de su tesis central sobre la violencia expuesta en su publicación seminal Communities of Violence: Persecution of Minorities in the Middle Ages (Princeton: Princeton University Press, 1996) para poner al descubierto ciertos hábitos de pensamiento en la historiografía sobre estas relaciones en la época medieval y moderna. Ambas publicaciones son representativas de posturas bien conocidas dentro del debate académico sobre las relaciones entre cristianos, judíos y musulmanes, unas relaciones que continúan siendo objeto de relectura por parte de los estudiosos (consúltese por ejemplo la reciente publicación de Catlos, Brian. Kingdoms of Faith: A New History of Islamic Spain. New York, N.Y.: Basic Books, 2018).

El esfuerzo por integrar dentro de un solo estudio los periodos medieval y moderno se hace visible no solamente en la publicación de Nirenberg sino también en el volumen coordinado por Maria Filomena Lopes de Barros y José Hinojosa Montalvo (Lopes de Barros, Maria Filomena-Hinojosa Montalvo, José (coord.) Minorias étnico-religiosas na Península Ibérica: período Medieval e Moderno. Actas do I Encontro Minorias no Mediterrâneo. Lisboa: Colibri; Évora: Centro Interdisciplinar de História, Culturas e Sociedades da Universidade; Alicante: Universidade de Alicante, 2008). Véanse también para los judíos y musulmanes bajomedievales, aunque con una mayor atención hacia los moriscos, las contribuciones a los volúmenes editados por José Alberto Rodrigues da Silva Tavim, Maria Filomena Lopes de Barros y Lúcia Liba Mucznik (Rodrigues da Silva Tavim, José Alberto-Lopes de Barros, Maria Filomena-Mucznik, Lúcia Liba (eds.) In the Iberian Peninsula and Beyond: A History of Jews and Muslims (15th-17th Centuries), 2 Vols. Newcastle upon Tyne:

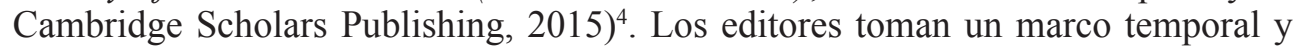
analítico amplio de las minorías, con referencias a grupos como los gitanos que a menudo no figuran en este tipo de publicaciones. En este volumen las contribuciones sobre mudéjares están firmadas por nombres bien conocidos como los de Isabel Montes Romero-Camacho, Ángel Luis Molina Molina, Jean-Pierre Molénat, Ana Echevarría Arsuaga, Maria Filomena Lopes de Barros y Vincent Barletta. En la misma línea encontramos Mota, Guilhermina (ed.) Minorias étnicas e religiosas em Portugal. História e Actualidade. Coimbra: Instituto de História Económica e Social, 2003. Finalmente cabe señalar el volumen editado por Matthias Tischler y Alexander Fidora (Tischler, Matthias-Fidora, Alexander (eds.) Christlicher NordenMuslimischer Süden: Ansprüche und Wirklichkeiten von Christen, Juden, und Muslimen auf der Iberischen Halbinsel im Hoch- und Spätmittelalter. Münster in Westfalen: Aschendorff, 2011) en el que encontramos un número de aportaciones al estudio de la transmisión del conocimiento y las relaciones entre comunidades.

Por último, debe nombrarse el estudio integral del islam en occidente (en Europa y en ambos hemisferios del continente americano) en el volumen editado por Roberto Tottoli (Tottoli, Roberto (ed.) Routledge Handbook of Islam in the West. New

$4 \quad$ Esta publicación incluye estudios conjuntos de musulmanes y judíos peninsulares y puede ser consultada en el repositorio digital de libre acceso Publicações do Cidehus (Centre Interdisciplinaire Histoire, Cultures et Sociétés de l'Université de Évora) http://books.openedition.org/cidehus/220 
York: Routledge, 2015). Esta publicación tiene el fuerte atractivo de reunir dentro de un único volumen contribuciones de destacados expertos entre los que se cuentan especialistas de la historia y de la cultura de los musulmanes peninsulares, como Mercedes García-Arenal (sobre el conocimiento islámico de los moriscos) o Anneliese Nef (sobre los mudéjares sicilianos). Particularmente relevante para el estudio de los mudéjares es la sección redactada por Alessandro Vanoli.

En el periodo bajo consideración ha habido una producción discreta de monografías sobre las relaciones entre comunidades religiosas en los territorios peninsulares cristianos sobre todo si se compara con los volúmenes editados, que son mucho más abundantes. Entre las primeras contamos con el interesante estudio sobre la práctica y la transmisión del conocimiento de la medicina entre comunidades -en particular, entre mudéjares y moriscos- de Luis García Ballester (García Ballester, Luis. Medicine in a Multicultural Society: Christian, Jewish and Muslim Practitioners in the Spanish Kingdoms, 1222-1610. Aldershot, U.K.: Ashgate Variorum, 2001) y con el monográfico sobre los mudéjares de Cataluña y Aragón (en el Thaghr al-Aqșā o "marca más lejana") de Brian Catlos (Catlos, Brian. The Victors and the Vanquished: Christians and Muslims of the Ebro Valley (Eleventh to Thirteenth Centuries). Cambridge, U.K.; New York: Cambridge University Press, 2004).

Se listan a continuación los volúmenes editados de mayor interés y se acompañan de algunas notas:

- Burns, Robert I.-Chevedden, Paul E. (eds.) Negotiating Cultures: Bilingual Surrender Treaties in Muslim-Crusader Spain. Leiden, Boston, Köln: Brill, 1999.

Destaca en la tercera parte el capítulo de Míkel de Epalza sobre la naturaleza de los pactos entre musulmanes y cristianos (' $a h d, \mathrm{pl}$. 'uhiud) que formaron la base de las comunidades mudéjares, o aljamas.

- Echevarría Arsuaga, Ana-Monferrer-Sala, Juan Pedro-Tolan, John (eds.) Law and Religious Minorities in Medieval Societies: Between Theory and Praxis/De la teoría legal a la práctica en el derecho de las minorías religiosas en la edad media. Turnhout: Brepols, 2016.

Esta publicación sobre la legislación de las minorías tiene un enfoque amplio que incluye no obstante aportaciones de interés sobre los mudéjares, en particular, la transmisión de la jurisprudencia islámica a través de sus jueces (cadíes) y expertos en religión (alfaquíes) (Ana Echevarría Arsuaga), la regulación de sus comunidades bajo las órdenes militares (Clara Almagro Vidal) y los pactos de regulación de las relaciones entre cristianos y mudéjares (Yolanda Moreno Moreno).

- Hames, Harvey J. (ed.) Jews, Muslims and Christians In and Around the Crown of Aragon: Essays in Honour of Professor Elena Lourie. Leiden, Boston: Brill, 2004.

Destacan aquí el análisis de David Nirenberg sobre matrimonios interconfesionales ("Love Between Muslim and Jew in Medieval Spain: A Triangular Affair") y el de Ana Echevarría Arsuaga sobre las estrategias de la identidad de los mudéjares 
("Vassal and Friend: Strategies of Mudejar Submission and Resistance to Christian Power in Castile").

- Herbers, Klaus-Jaspert, Nikolas (eds.) Integration-Segregation-Vertreibung: Religiöse Minderheiten und Randgruppen auf der Iberischen Halbinsel (7.-17. Jahrhundert). Berlín: LIT Verlag, 2011.

En esta publicación redactada íntegramente en alemán por dos editores bien conocidos dentro del campo de estudio de la edad media encontramos un buen número de trabajos de interés sobre los musulmanes en los territorios cristianos, como los dedicados a su integración, de Maria Filomena Lopes de Barros y de José Ramón Hinojosa Montalvo.

- Meyerson, Mark. D.-English, Edward D. (eds.) Christians, Muslims, and Jews in Medieval and Early Modern Spain. Interaction and Cultural Change. Notre Dame [Ind.]: University of Notre Dame Press, 2000.

Destacan la aportación al estado de la cuestión de Robert I. Burns (véase más abajo, 4) y el estudio de Nirenberg sobre fronteras religiosas y sexuales.

- Mutgé i Vives, Josefina-Salicrú i Lluch, Roser-Vela i Aulesa, Carles (eds.) La Corona catalanoaragonesa, l'islam i el món mediterrani: estudis d'història medieval en homenatge a la doctora Maria Teresa Ferrer i Mallol. Barcelona: Consejo Superior de Investigaciones Científicas, Institución Milà i Fontanals, Departament de ciències històriques-estudis medievals, 2013.

Esta publicación incluye trabajos redactados en catalán, castellano e italiano y en ella destaca el estudio de Juan Antonio Barrio Barrio sobre las relaciones de sociabilidad entre los conversos de judío y los mudéjares en el reino de Valencia a finales del siglo XV.

- Valdeón Baruque, Julio (dir. congr.) Cristianos, musulmanes y judios en la España medieval: de la aceptación al rechazo. Valladolid: Ámbito Ediciones, 2004.

Dentro de este volumen destaca la aportación sobre los mudéjares de Miguel Ladero Quesada y la discusión sobre la convivencia de Júlio Valdeón Baruque.

\subsection{Trabajos sobre comunidades mudéjares}

En este apartado se tratan los trabajos en los que los mudéjares son el principal objeto de estudio. Se presentan primero las monografias, las de conjunto y las síntesis (2.2.1) y las dedicadas a una o varias de las comunidades locales, o aljamas (2.2.2). Luego se presta atención a los volúmenes editados (2.2.3). Solo tenemos conocimiento de dos artículos sobre mudéjares en regiones no peninsulares (Davis-Secord, Sarah. "Muslims in Norman Sicily: The Evidence of Imām al-Māzarī's Fatwās." Mediterranean Studies 16 (2007): 46-66 y Nef, Anneliese. "Muslims and Islam in Sicily from the mid-XI ${ }^{\text {th }}$ until the end of the XII ${ }^{\text {th }}$ century: Contemporary Perceptions 
and Today's Interpretations." En Tottoli, Roberto (ed.) Routledge Handbook of Islam in the West. Routledge: Abingdon-New York, 2014, pp. 55-69).

\subsubsection{Trabajos de síntesis}

El siglo veintiuno produce estudios sobre mudéjares que tratan sus comunidades desde unas perspectivas de integración y de síntesis que se apartan de las adoptadas en trabajos pioneros como los de Macho y Ortega, Ladero Quesada y Boswell (véase arriba, 1). De este modo, la publicación en 1990 del recientemente fallecido Leonard Patrick Harvey representa uno de los primeros intentos genuinos de estudiar los mudéjares peninsulares de forma conjunta, así como de sus comunidades moriscas tras las conversiones, de forma diacrónica (Harvey, Leonard Patrick. Islamic Spain, 1250 to 1500. Chicago: University of Chicago Press, 1990). Esta es una propuesta que el mismo autor extenderá para el periodo previo a la expulsión de los moriscos (Muslims in Spain, 1500-1614. Chicago: Chicago University Press, 2005). Por otra parte, los dos volúmenes de José Ramón Hinojosa Montalvo cubren el periodo mudéjar en la península en toda su extensión territorial y temporal, aunque como en el caso de Harvey, los musulmanes portugueses reciben una atención menor (Hinojosa Montalvo, José Ramón. Los mudéjares: la voz del islam en la España cristiana, 2 Vols. Teruel: Centro de Estudios Mudéjares, 2002). Esta laguna se cubre con la obra fundamental de Maria Filomena Lopes de Barros y con los varios artículos a los que nos referiremos más abajo que tratan intensivamente sobre los mudéjares del reino de Portugal (Lopes de Barros, Maria Filomena. Tempos e espaços de mouros: a minoria muçulmana no reino português (séculos XII a XV). Lisboa: Fundação Calouste Gulbenkian para a Ciência e a Tecnologia, 2007). Dos publicaciones que brillan por su capacidad de unir síntesis con trabajo bien fundamentado y de utilidad son las de Mercedes García-Arenal (García-Arenal, Mercedes. La diáspora de los andalusíes. [Enciclopedia del mediterráneo]. Barcelona: Cidob Edicions-Icaria Editorial, 2003; para el tema que nos ocupa se destaca el tercer capítulo, así como la bibliografía comentada final) y Ana Echevarría Arsuaga (Echevarría Arsuaga, Ana. La minoría islámica de los reinos cristianos medievales: moros, sarracenos, mudéjares. Málaga: Editorial Sarriá, 2004). Aunque los mudéjares ocupen en ellas un lugar secundario cabe también destacar los interesantes volúmenes de la colección "Enciclopedia del mediterráneo" de Manuela Marín (Marín, Manuela. Al-Andalus y los andalusies, 2000) y Maribel Fierro Bello (Fierro Bello, Maribel. Al-Andalus: saberes e intercambios culturales, 2001). Por otro lado, Brian Catlos emprende la tarea de llevar los límites del trabajo de conjunto sobre los mudéjares a su máxima expresión en una publicación que no se limita a sus comunidades en la península ibérica, sino que incluye a los musulmanes que vivieron bajo el dominio cristiano en el Mediterráneo oriental y en lugares como Sicilia y Hungría (Catlos, Brian. Muslims of Medieval Latin Christendom, c.10501614. Cambridge: Cambridge University Press, 2014).

\subsubsection{Trabajos sobre los mudéjares de los diferentes reinos peninsulares}

La mayor atención en los trabajos sobre aljamas ha sido dirigida a las de la corona de Aragón y de Castilla, seguidas por las de los reinos de Valencia. Destacan sobre estas últimas las publicaciones de Maria Josep Fortea (Fortea, Maria Josep. 
Senyors cristians, vassalls musulmans: Nàquera i els naquerans a les darreries del segle $X V$. Benicull de Xúquer: Editorial 7 i mig, 1999); de Miguel-Àngel González i Hernández (González i Hernández, Miguel-Àngel. Musulmans, jueus $i$ cristians a les terres de Vinalopó (1401-1594). Petrer (Al.): Centre d'Estudis Locals del Vinalopó, 2004) y el interesante estudio de la aljama de Xàtiva de Isabel A. O'Connor (O'Connor, Isabel A. A Forgotten Community: The Mudejar Aljama of Xátiva 1240-1327. Leiden, Boston: Brill, 2003). No se han publicado monografías sobre aljamas navarras, gallegas o portuguesas con excepción del trabajo anterior sobre Lisboa a cargo de Maria Filomena Lopes de Barros (Lopes de Barros, Maria Filomena. A comuna muçulmana de Lisboa: Sécs. XIV e XV. Lisboa: Hugin Editores, 1998) y el estudio de conjunto de la misma autora que hemos señalado arriba (2.2.1). Contamos con contribuciones destacadas sobre el reino de Granada que se incluyen en las menciones a los volúmenes editados en el apartado siguiente.

Los estudios sobre aljamas aragonesas arrojan luz sobre varios aspectos relacionados con la composición interna, la estructuración y el funcionamiento social de sus comunidades basándose firmemente en los métodos y los datos aportados por la prosopografía y en las fuentes documentales (en su mayoría cristianas). Tómense aquí como ejemplo las publicaciones de Anchel Conte Cazcarro (Conte Cazcarro, Anchel. La aljama de moros de Barbastro. Barbastro (Hu.): Ánchel Conte Cazcarro, 2013), Germán Navarro Espinach y Concepción Villanueva Morte (Navarro Espinach, Germán-Villanueva Morte Concepción. Los mudéjares de Teruel y Albarracin: familia, trabajo y riqueza en la Edad Media. Teruel: Centro de Estudios Mudéjares, 2003) y Pascual Ortega Pérez (Ortega Pérez, Pascual. Musulmanes en Cataluña: las comunidades musulmanas de las encomiendas templarias y hospitalarias de Ascó y Miravet (siglos XII-XIV). Barcelona: Consejo Superior de Investigaciones Científicas, Institución Milà i Fontanals, Departamento de estudios medievales, 2000).

Los trabajos sobre aljamas castellanas siguen líneas de trabajo muy parecidas, aunque aquí cobra una mayor importancia la evidencia arqueológica y epigráfica y se aprecia un mayor interés por explicar la evolución de las comunidades desde sus orígenes hasta las conversiones de los moriscos. Entre las monografías más destacadas se encuentra la de Miguel Gómez Vozmediano (Gómez Vozmediano, Miguel. Mudéjares y moriscos en el Campo de Calatrava: reductos de convivencia, tiempos de intolerancia (siglos $X V$-XVII). Ciudad Real: Diputación Provincial de Ciudad Real, 2000); Miguel Romero Saiz (Romero Saiz, Miguel. Mudéjares y moriscos en Castilla-La Mancha: aproximación a su estudio. [Piedrabuena (Ciudad Real)]: Ediciones Llanura, 2007) y la de Ana Echevarría Arsuaga (Echevarría Arsuaga, Ana. The City of the Three Mosques: Ávila and its Muslims in the Middle Ages. Wiesbaden: Reichert, 2011). Es la comunidad mudéjar en la ciudad de Ávila la que ha sido objeto de varios estudios por esta autora, que en ocasiones ha colaborado con otros autores, como es el caso del catálogo ligado a la exposición sobre mudéjares y moriscos abulenses (Jiménez Gadea, Javier et al. (eds.) La memoria de Alá: mudéjares y moriscos de Ávila. Valladolid: Castilla Ediciones, 2011). Otras contribuciones que deben de mencionarse son las incluidas en el catálogo sobre los mudéjares de Valencia editado por Benítez Sánchez-Blanco, Rafael et al. (eds.) Entre terra i fe: els musulmans al regne cristià de València (1238-1609). València: Universitat de València, 2009. 


\subsubsection{Volúmenes editados}

Entre las ideas aportadas por las monografías que acabamos de mencionar está la noción de la marcada diversidad interna de las comunidades de mudéjares y de moriscos y su distinta incorporación dentro de la sociedad cristiana. Las contribuciones al volumen editado por Ana Echevarría Arsuaga exploran esta variedad y lo hacen a través del estudio de trayectorias o biografías mudéjares individuales entre las que figuran las de algunos sabios (ulemas), expertos en jurisprudencia (alfaquíes) y mediadores y transmisores del saber. También se exploran las identidades de los miembros de las élites y sus redes, así como las redes familiares (Echevarría Arsuaga, Ana. Biografías mudéjares o La experiencia de ser minoría: biografias islámicas en la Españas cristiana. Madrid: Consejo Superior de Investigaciones Científicas, 2008).

Por otro lado, destaca por su perspectiva comparativa un segundo volumen coordinado por esta misma autora junto con Adela Fábregas García que se centra en los modelos organizativos poblacionales en la Granada nazarí y las aljamas castellanas (Echevarría Arsuaga, Ana-Fábregas García, Adela (coord.) De la alquería a la aljama. Madrid: Universidad Nacional de Educación a Distancia, 2016). Este mismo enfoque caracteriza algunas contribuciones a los tres volúmenes sobre el reino de Granada editados por Manuel Barrios Aguilera y Rafael Gerardo Peinado Santaella (Barrios Aguilera, Manuel-Peinado Santaella, Rafael Gerardo (eds.) Historia del reino de Granada, 3 Vols. Granada: Universidad de Granada, 2000; las últimas secciones del primer volumen y el segundo volumen son de especial interés para el tema que aquí nos ocupa). Granada se compara con Castilla y con Valencia en el volumen coordinado por Manuel Barrios Aguilera y Ángel Galán Sánchez (Barrios Aguilera, Manuel-Galán Sánchez, Ángel (coord.) La historia del reino de Granada a debate: viejos y nuevos temas: perspectivas de estudio. Málaga: Editorial Actas, 2004).

\subsubsection{Publicaciones sobre fuentes documentales relativas a mudéjares}

El uso de fuentes árabes y aljamiadas (i.e. lenguas romances en caracteres árabes) compuestas y copiadas por los miembros de las propias comunidades de mudéjares ha tomado fuerza entre los métodos de investigación en las últimas décadas. Manuscritos, códices y documentos notariales, entre otros, se han incorporado a las fuentes cristianas y archivísticas que tradicionalmente fundamentaban la investigación. El avance de los proyectos de digitalización ha hecho posible la creación de la página web del Consejo Superior de Investigaciones Científicas (CSIC) que contiene un importante repositorio de manuscritos en lenguas orientales y en aljamía conservados en los diferentes centros de los que se compone este organismo (http://manuscripta.bibliotecas.csic.es). Asimismo, contamos con catálogos como el de la exposición celebrada en Alejandría y Barcelona en 2002 de los fondos árabes en Cataluña, editado por Josep Giralt (Jawāhir maktūba: majmū āt al-mașādir wa-l-marāji 'alárabiyya fì qatalūniyya/Joyas escritas: Los fondos bibliográficos árabes de Catalu$\tilde{n} a$. Barcelona: Institut Català de la Mediterrània, 2002). El libre acceso $\mathrm{y}$ el cada vez mayor y mejor conocimiento de las fuentes manuscritas han abierto perspectivas nuevas sobre los mudéjares de las que nos ocuparemos en la tercera sección de la presente bibliografía.

Esencial para el estudio de los musulmanes peninsulares, en particular de los valencianos, es el magnífico y cuidadoso trabajo de María del Carmen Barceló To- 
rres y Ana Labarta Gómez (Barceló Torres, María del Carmen-Labarta Gómez, Ana. Archivos moriscos: textos árabes de la minoría islámica valenciana 1401-1608. València: Universitat de València, 2009). A cargo de las mismas autoras es otra publicación de fuentes árabes, en este caso, poéticas (Cancionero morisco: poesía árabe de los siglos XV y XVI. València: Ángeles Carrillo Baeza, 2016). En lo referente a las fuentes documentales cristianas disponemos también de nuevas e importantes aportaciones como los volúmenes de Maria Teresa Ferrer i Mallol et al. (Ferrer i Mallol, Maria Teresa et al. Fuentes documentales para el estudio de los mudéjares. Teruel: Centro de Estudios Mudéjares, 2005) y de Adel Sidarius (Sidarus, Adel (ed.) Fontes da História de al-Andalus e do Gharb (Lisboa: Instituto de Investigaçao Científica e Tropical, Centro de Estudos Africanos e Asiáticos, 2000). No podemos concluir este apartado sin mencionar la publicación sobre documentación aragonesa de María Blanca Basáñez Villaluenga (Basáñez Villaluenga, María Blanca. Las morerías aragonesas durante el reinado de Jaime II: catálogo de la documentación de la Cancillería Real. Volumen I (1291-1310). Teruel: Centro de Estudios Mudéjares, 1999) así como la futura publicación de la por otro lado conocida investigadora de los manuscritos árabes y aljamiados de los moriscos y su codicología, Núria de Castilla, sobre los manuscritos mudéjares y moriscos en Francia (Manuscrits mudéjars et morisques en France. Roma, Istituto per l'Oriente C.A. Nallino-CNRS).

\section{Temas de investigación dentro de los estudios mudéjares}

La evaluación cuidadosa de la literatura publicada permite distinguir cuatro áreas centrales de interés dentro de los estudios mudéjares: (3.1) la organización de las comunidades o aljamas, (3.2) la identidad religiosa de los mudéjares y la práctica del islam, (3.3) la transmisión del conocimiento, el lenguaje y la producción manuscrita y (3.4) las minorías de mujeres y esclavos. Son las relaciones entre las minorías mudéjares, las minorías judías y la mayoría cristiana uno de los principales hilos conductores entre las secciones, en particular entre las tres primeras. Como se verá, las nuevas perspectivas sobre las relaciones dentro y entre las élites y la transmisión del conocimiento sugieren que la articulación de estas relaciones habría respondido a preocupaciones distintas de la religión. El grueso de esta sección se compone de artículos de revistas, aunque sin duda las monografías y volúmenes editados referidos arriba ofrecen importantes aportaciones a muchos de los temas que se señalan aquí. Por la brevedad que se impone, se incluyen solo algunas contribuciones a números especiales de revista como el coordinado por Manuel Ruzafa García en la Revista d'història medieval 12 (2003) [Los mudéjares valencianos y peninsulares] y las Actas de los Simposios Internacionales de Mudejarismo organizados periódicamente por el Centro de Estudios Mudéjares de Teruel. Remito pues al lector interesado a Actas VII (1999), VIII (2002), IX (2004) y XI (2009), y muy particularmente, Actas X (2007) dedicada al balance de los estudios mudéjares entre 1975-2005.

\subsection{Organización de las comunidades o aljamas}

La organización de las aljamas se ha estudiado en torno a tres ejes principales: las familias y élites de poder, la movilidad de los miembros de las comunidades mudéjares y la jurisprudencia. 
Conte Cazcarro, Ánchel. "Los moros de Naval (Nabal) en los siglos XV y XVI." Aragón en la Edad Media 24 (2013): 91-139.

Ferrer i Mallol, Maria Teresa. "L'aljama islàmica de Tortosa a la Baixa Edat Mitjana." Recerca. Arxiu Històric Comarcal de les Terres de l'Ebre 7 (2003): 179-231.

González Paz, Carlos A. "Sarracenos, moros, mudéjares y moriscos en la Galicia medieval." Cuadernos de Estudios Gallegos 51, No. 117 (2004): 281-312.

Lopes de Barros, Maria Filomena. "Os mouros de Santarém: a comuna e os espaços." En Catálogo da Exposição Santarém e o Magreb: encontro secular (9701578). Santarem: Câmara Municipal de Santarem, 2004, pp. 60-67.

Molénat, Jean-Pierre. "Communautés mudéjares de Castille et de Portugal. Le cas de Tolède et Lisbonne, XIIe-XVe siècles.” En Société des historiens médiévistes de l'enseignement supérieur public, 33 e congrès, Madrid, 2002. L'expansion occidentale (XIe-XVe siècles). Formes et conséquences. XXXIII Congrès de la SHMES. Madrid: Casa de Velázquez, 23-26 mai 2002. Paris: Publications de la Sorbonne, 2003, pp. 215-227.

\subsubsection{Familias, élites y redes de poder}

Los estudios muestran que los lazos entre familias mudéjares se mantuvieron a pesar de las largas distancias y de las crecientes restricciones de los cristianos sobre sus minorías. Trabajos recientes como los de Ana Echevarría Arsuaga (Echevarría Arsuaga, Ana. "Familia, poder y tradición entre los mudéjares de la Península Ibérica." En Actas del XIII Simposio Internacional de Mudejarismo: Teruel, 4-5 de Septiembre de 2014. Teruel: Centro de Estudios Mudéjares, 2017, pp. 111-138) tratan la evolución entre la familia andalusí y la mudéjar, señalando que estamos ante cambios graduales y no ante rupturas, así como adentrándose en cuestiones de creciente interés como es la importancia de las mujeres dentro de las comunidades (véase en relación a las mujeres el apartado 3.4 abajo). Hay una creciente evidencia de la existencia de redes de aljamas interconectadas en amplias áreas del territorio que no se circunscriben a las fronteras políticas entre los diferentes reinos. De este modo encontramos ramas de una misma familia en los distintos reinos cristianos y en los territorios musulmanes del reino de Granada; ocasionalmente, también las encontramos allende los territorios peninsulares. Los máximos representantes de las comunidades mudéjares, los alcaldes o alcaldes mayores, pertenecían a estas familias y tenían asignada la jurisprudencia de las aljamas del reino, puesto que ejercían en la intersección entre la aljama y las estructuras de poder cristianas debido a que era el rey quien nombraba sus cargos. En ocasiones, los alcaldes de los distintos reinos competían por el poder, como es el caso de algunos miembros de las familias Bellvís y Xarafí. Hay una mayor evidencia de que los miembros de las élites musulmana, cristiana y judía mantuvieron vínculos que parecen haber sido más estrechos y sostenidos en el tiempo de lo que se pensó anteriormente. Entre los ejemplos más significativos sobre los que han arrojado luz las publicaciones recientes se encuentran los diplomáticos y los mediadores que desempeñaron funciones de traductores dentro de la corte, así como la guardia musulmana al servicio de los cristianos (consúltese el monográfico de Echevarría Arsuaga, Ana. Knights on the Frontier: The Moorish Guard of the Kings of Castile (1410-1467). Leiden, Boston: Brill, 2009). Fundamental para el conocimiento de las redes entre los miembros de las familias y entre quienes tuvieron autoridad religiosa sobre las aljamas (como por ejemplo los 
alfaquíes), es el monográfico de Kathryn A. Miller (Miller, Kathryn A. Guardians of Islam: Religious Authority and Muslim Communities of Late Medieval Spain. Columbia: Columbia University Press, 2008). Listamos a continuación algunas publicaciones adicionales de interés:

- Abella Samitier, Juan. "Una familia de mudéjares aragoneses en el tránsito de la Edad Media a la Moderna: los Xama de Zaragoza." En la España Medieval 28 (2005): 197-212.

- Echevarría Arsuaga, Ana. "Las aljamas mudéjares castellanas en el siglo XV: redes de poder y conflictos internos." Espacio, Tiempo y Forma. Serie III, Historia Medieval: revista de la Facultad de Geografia e Historia 14 (2001): 93-112.

- Echevarría Arsuaga, Ana. "De cadí a alcalde mayor: la élite judicial mudéjar en el siglo XV (I).” Al-Qantara: Revista de Estudios Árabes 24, No. 1 (2003): 139168.

- Echevarría Arsuaga, Ana. "De cadí a alcalde mayor: la élite judicial mudéjar en el siglo XV (II)." Al-Qanțara: Revista de Estudios Árabes 24, No. 2 (2003): 273289.

— Ferrer i Mallol, Maria Teresa. "L'alfaquí Mahomat Alhaig i la lluita pel poder a la morería d'Elx (1448-1457)." Revista d'història medieval [Volumen monográfico Los mudéjares valencianos y peninsulares] 12 (2001-2002): 185-240.

- Mayor, Rafael-Echevarría Arsuaga, Ana. "Hermanos y cofrades en la aljama de Toledo a principios del siglo XV." Anaquel de Estudios Árabes 26 (2015):163185.

— Molénat, Jean-Pierre. "L'élite mudéjare de Tolède aux XIVe et XVe siècle. Alfaquís, alcaldes et alcaldes mayores de moros." En Barhtélemy, Dominique-Martin, Jean-Marie (coord.) Liber Largitorius. Études d'histoire médievales offertes à Pierre Toubert par ses élèves. Genève: Droz, 2003, pp. 563-577.

- Molénat, Jean-Pierre. "La question de l'élite mudéjare dans la Péninsule Ibérique médievale." En Felipe Themudo Barata (ed.) Elites e redes clientelares na Idade Média: problemas metodológicos: Actas du coloquio. Lisbonne-Évora: Ed. Colibri-CIDEHUS, 2001, pp. 45-53.

- O'Connor, Isabel A. "Mudejars helping other Mudejars in the Kingdom of Valencia." Al-Masāq: Islam and the Medieval Mediterranean 17, No. 1 (2005): 99108.

- Ortego Rico, Pablo. "Elites y conflictividad en el seno de las aljamas mudéjares castellanas a fines de la Edad Media: exención tributaria y redes clientelares." Hispania 75, No. 250 (2015): 505-536.

\subsubsection{Movilidad}

La movilidad fue crucial para los mudéjares para mantener sus relaciones con otros musulmanes dentro y fuera de la península ibérica. Si bien los cristianos impusieron restricciones prohibiendo a los mudéjares abandonar sus lugares de origen, la evidencia es cada vez más firme de que éstos consiguieron viajar cortas y largas distancias hasta una fecha tardía. Un ejemplo de gran importancia a este respecto es el reciente descubrimiento de manuscritos sobre la peregrinación a La Meca de Omar Patún entre 1491-1495 (y su regreso a su ciudad natal Ávila tres años tras la toma de Granada por los cristianos). El viaje de Patún ha sido editado por Casassas Canals, 
Xavier et al. (De Ávila a la Meca: el relato del viaje de Omar Patún 1491-1495. Valladolid: Ediciones Universidad de Valladolid, 2017) y es inminente la edición crítica a cargo de Pablo Roza Candás de los manuscritos existentes (Colección de Literatura Española Aljamiado-Morisca (CLEAM) 16, Seminario de Estudios Árabo-Románicos, Universidad de Oviedo). Consúltense también de estos dos autores Casassas Canals, Xavier. "La riḥla de Omar Patún: el viaje de peregrinación a la Meca de un musulmán de Ávila a finales del siglo XV (1491-1495)." Espacio, tiempo y forma. Serie III, Historia Medieval: revista de la Facultad de Geografia e Historia 28 (2015): 221-254 y Roza Candás, Pablo. "De Ávila a La Meca: notas en torno a una rihla aljamiada inédita." En Actas del XIII Simposio Internacional de Mudejarismo: Teruel, 4-5 de Septiembre de 2014. Teruel: Centro de Estudios Mudéjares, 2017, 353-364).

Asimismo, José Hinojosa Montalvo y José Enrique López de Coca Castañer han dedicado sendos artículos a los desplazamientos de mudéjares (Hinojosa Montalvo, José. "Desplazamiento de mudéjares valencianos entre la gobernación de Orihuela y Granada durante el siglo XV: la ruta legal." Aragón en la Edad Media 14-15 (1999): 743-757; López de Coca Castañer, José Enrique. "La emigración mudéjar al reino de Granada en tiempo de los Reyes Católicos." En la España Medieval 26 (2003): 203226, esta última en la que se demuestra el flujo migratorio a Granada de mudéjares provenientes de otras regiones, como Castilla y Aragón, a pesar de las prohibiciones reales que lo impedían). Una publicación que resulta del reciente interés de los estudiosos por la movilidad mudéjar y morisca y la circulación de personas, objetos, manuscritos y conocimiento entre sus comunidades es el volumen en prensa editado por Ana Echevarría Arsuaga, Alice Kadri y Yolanda Moreno Moreno (Circulaciones mudéjares y moriscas. Madrid: Consejo Superior de Investigaciones Científicas, 2018).

\subsubsection{Jurisprudencia islámica}

Otra área de fuerte interés dentro de la disciplina de los estudios mudéjares ha sido la posición de sus minorías dentro de la comunidad musulmana y su regulación según la ley islámica. Se observan importantes avances en el conocimiento de los textos que circularon dentro de las aljamas y también entre los cristianos. Las conocidas como "leyes de moros", o adaptación aljamiada del tratado jurídico en árabe del jurista Ibn al-Djallāb (s. X) como ya hizo notar Alfonso Carmona González, han sido estudiadas por Soha Abboud-Haggar y también en su circulación manuscrita por Juan Carlos Villaverde Amieva (Abboud-Haggar, Soha. El tratado jurídico de al-Tafrī‘ de Ibn al-Ğallāb: manuscrito aljamiado de Almonacid de la Sierra. Edición, estudio, glosario y confrontación con el original árabe, 2 Vols. Zaragoza: Institución "Fernando el Católico", Consejo Superior de Investigaciones Científicas, 1999 y recientemente por la misma autora "Un resumen del tratado jurídico de alTafrī : el manuscrito árabe 1233 del Monasterio de El Escorial y su supuesta relación con Leyes de Moros." Espacio, Tiempo y Forma. Serie III, Historia Medieval: revista de la Facultad de Geografia e Historia 31 (2018): 29-43; Villaverde Amieva, Juan Carlos. "Un papel de Francisco Antonio González sobre "códices escritos en castellano con caracteres árabes" (Real Academia de la Historia año 1816) y noticia de las copias modernas de "Leyes de Moros"." En Suárez García, Raquel-Ceballos Viro, Ignacio (coord.) Aljamías: in memoriam Álvaro Galmés de Fuentes y Iacob M. 
Hassán. Gijón: Trea, 2012, pp. 131-214). Por otro lado, María del Carmen Barceló Torres editó en 1989 la obra de jurisprudencia anónima de origen valenciano titulada "llibre de suna e xara", un texto que parece haber sido utilizado no solamente por musulmanes sino también por los cristianos interesados en conocer las leyes propias de sus vasallos musulmanes para así poder gobernarlos mejor. Ahora disponemos de una segunda edición de este "llibre" a cargo de Vicente García Edo y Vicente Pons Alós (García Edo, Vicente-Pons Alós, Vicente. Suna e Xara: la ley de los mudéjares valencianos (siglos XIII-XV). Castellón: Universidad Jaume I, 2009).

No solo sabemos más sobre la regulación interna de las aljamas, sino que también contamos con importantes contribuciones recientes sobre las opiniones que los juristas musulmanes en las tierras del islam tuvieron de los mudéjares. La sólida tesis de Jocelyn Hendrickson sitúa las fatwās, o opiniones legales del jurista al-Wansharīsī dentro del contexto peninsular norteafricano (Hendrickson, Jocelyn. "The Islamic Obligation to Emigrate: Al-Wansharīsī's Asnā al-matājir Reconsidered." PhD diss., Emory University (Atlanta), 2009). En su monografía, Alan Verskin argumenta por su parte, aunque no de forma completamente convincente, que estas opiniones deben leerse principalmente y casi exclusivamente a la luz del contexto ibérico y de los eventos ligados a la "reconquista" cristiana (Verskin, Alan. Islamic Law and the Crisis of the Reconquista: The Debate on the Status of Muslim Communities in Christendom. Leiden, Boston: Brill, 2015 y del mismo autor "The Evolution of the Mālikī Jurists' Attitudes to the Mudéjar Leadership.” Der Islam 90, No. 1 (2013): 44-64). Es también útil la síntesis de Jean-Pierre Molénat en la que, como él mismo señala, suscribe las opiniones de académicos que han analizado el tema en publicaciones previas, tales como Manuela Marín, Khalid Abou el Fadl y Maribel Fierro (Molénat, Jean-Pierre. "Le problème de la permanence des musulmans dans les territoires conquis par les chrétiens, du point de vue de la loi islamique." Arabica 48, No. 3 (2001): 392-400). Por otra parte, Devin Steward logra identificar al mufti de Orán, autor de una opinión legal $(f a t w \bar{a})$ bien conocida que reconoce a los musulmanes convertidos al cristianismo, los moriscos, la posibilidad de practicar el islam en secreto y que Steward contextualiza como respuesta a otros juristas como alWansharīsī (Steward, Devin. "The identity of "the Muftī of Oran", Abū l- 'Abbās Aḥmad b. 'Alī Jum 'ah al-Maghrāwī al-Wahrānī (d. 917-1511).” Al-Qanțara: Revista de Estudios Árabes 27 (2006): 265-301).

Finalmente, deben de citarse los tres volúmenes árabes hallados en Cútar (Málaga) en 2003 que pertenecieron al alfaquí e imán de esta localidad, Muḥammad b. 'Alī b. Muhammad al-Djayyār al-Anșārī, y que fueron en parte copiados por él en la segunda mitad del siglo XV. Estos textos arrojan luz sobre las obras que conformaron la biblioteca de un jurista mudéjar de la época y sobre su formación para el cargo, teniendo en cuenta que, como era habitual, este cargo también incluía el ejercicio de tareas relacionadas con el liderazgo religioso de su comunidad. Muestra de esta doble función son los materiales de contenido jurídico-religioso en estos volúmenes que incluyen un Corán almohade (El corán de Cútar, Málaga. Estudio introductorio, 2 Vols. Sevilla: Consejería de Obras Públicas y Transportes y Consejería de Cultura de la Junta de Andalucía, Fundación tres Culturas del Mediterráneo, 2009 (publicación facsímil)) y dos obras de miscelánea (véanse Calero Secall, María Isabel. "Los manuscritos árabes de Málaga: los libros de un alfaquí de Cútar del siglo XV." En Viguera Molins, María Jesús-Castillo Castillo, Concepción (eds.) Los manuscritos árabes en España y Marruecos. Homenaje de Granada y Fez a Ibn Jaldún. Actas del 
congreso internacional (Granada, 2005). Granada-Sevilla: Junta de Andalucía, Fundación El Legado Andalusí, 2006, pp. 151-174; Calero Secall, María Isabel. "Muhammad al-Ŷayyār, un alfaquí a través de los manuscritos de Cútar." En Echevarría Arsuaga, Ana. Biografias mudéjares o La experiencia de ser minoría: biografías islámicas en la España cristiana. Madrid: Consejo Superior de Investigaciones Científicas, 2008, pp. 385-416; y más recientemente, Calero Secall, María Isabel et al. Los Manuscritos Nazaries De Cútar (Málaga): Documentos y estudios. Málaga: Universidad de Málaga, 2016. Véanse también Arias Torres, Juan Pablo. "Un fragmento del Kitāb al-Muktafà de al-Dānī entre los libros árabes de Cútar (Málaga)/A fragment of the Kitāb al-Muktafà by al-Dānī among the Arabic manuscripts from Cútar (Málaga)." Anaquel de Estudios Árabes 26 (2015): 19-28, así como las publicaciones sobre algunos textos poéticos en estos volúmenes de Barceló Torres, María del Carmen. "Endechas por la pérdida de al-Andalus en dos zéjeles de Cútar/Lament for the Loss of al-Andalus in two Zajal from Cútar." Al-Qanțara: Revista de Estudios Árabes 33, No. 1 (2012): 169-199 y Barceló Torres, María del Carmen-Labarta Gómez, Ana. ““Ṭawq al-Ḥamāma”: un muwaššah apocalíptico.” En Rius Piniés, Mònica-Romo, Ėlia-Bejarano, Ana María-Consoli, Erica (eds.) Traducir el mundo árabe. Homenaje a Leonor Martínez Martín. Barcelona: Publicacions i Edicions de la Universitat de Barcelona, D.L. 2014, pp. 93-131).

\subsection{Identidad religiosa de los mudéjares y práctica del islam}

\subsubsection{Identidad religiosa mudéjar}

La organización de las comunidades mudéjares está en estrecha relación con otra área que ha despertado un gran interés, a saber, la construcción de la identidad de los mudéjares en tanto que musulmanes dentro de una sociedad de mayoría cristiana. Algunos títulos de publicaciones dan buena idea de este interés (Martínez Almira, María Magdalena. "La noción de umma entre los mudéjares que participaron en las Germanías.” En Szászdi León-Borja, István-Galende Ruíz, María Jesús (coord.) Imperio y tiranía: la dimensión europea de las Comunidades de Castilla. Valladolid: Ediciones Universidad de Valladolid, 2013, pp. 197-234; Villanueva Zubizarreta, Olatz-Araus Ballesteros, Luis. "La identidad musulmana de los mudéjares de la Cuenca del Duero a finales de la Edad Media: aportaciones desde la aljama de Burgos." Espacio, Tiempo y Forma. Serie III, Historia Medieval: revista de la Facultad de Geografía e Historia 27 (2014): 525-546; Bernabé Pons, Luís. "Dixo un 'alim": Cultural Patterns in Late Spanish Islam." En Rodrigues da Silva Tavim, José Alberto-Lopes de Barros, Maria Filomena-Mucznik, Lúcia Liba (eds.) In the Iberian Peninsula and Beyond: A History of Jews and Muslims (15th-17th Centuries), 2 Vols. Newcastle upon Tyne: Cambridge Scholars Publishing, 2015; Vol. 1, pp. 266286).

Una de las reflexiones más importantes que aportan estos estudios es la idea de que los mudéjares consiguieron mantener su adhesión al islam, como se puede ver en la preservación de sus nombres islámicos y en sus documentos internos escritos en árabe, algunos de reuniones de sus comunidades (Lopes de Barros, Maria Filomena. "Nomear e ser nomeado. A onomástica dos muçulmanos portugueses no processo identitário." En Lopes de Barros, Maria Filomena-Hinojosa Montalvo, José (coord.) Minorias étnico-religiosas na Península Ibérica: periodo Medieval e Mo- 
derno. Actas do I Encontro Minorias no Mediterrâneo. Lisboa: Colibri; Évora: Centro Interdisciplinar de História, Culturas e Sociedades da Universidade; Alicante: Universidade de Alicante, 2008, pp. 309-322; Echevarría Arsuaga, Ana-Mayor, Rafael. "Las actas de reunión de una cofradía islámica de Toledo: una fuente para el estudio de los mudéjares toledanos. Años 1402-1414." Boletín de la Real Academia de la Historia 207, No. 2 (2010): 257-293). Disponemos también de más datos sobre las prácticas religiosas de sus minorías religiosas gracias al estudio de lápidas y epígrafes, sobretodo en regiones como Castilla en las que el islam tardío había tradicionalmente recibido una menor atención (Echevarría Arsuaga, Ana. "Islamic Confraternities and Funerary Practices: Hallmarks of Mudejar Identity in the Iberian Peninsula?"Al-Masaq: Islam and the Medieval Mediterranean 25, No. 3 (2013): 345-368; Jiménez Gadea, Javier. "Acerca de cuatro inscripciones árabes abulenses." Cuadernos abulenses 31 (2002): 25-72 y del mismo autor "Estelas funerarias islámicas de Ávila: clasificación e inscripciones". Espacio, tiempo y forma. Serie I, Prehistoria y Arqueología: revista de la Facultad de Geografía e Historia 2 (2009): 221267).

\subsubsection{Corán, literatura religiosa y predicación}

La vitalidad del islam mudéjar se evidencia en los elementos que acabamos de mencionar y también en la circulación tardía de originales y de copias árabes contemporáneas del Corán entre sus comunidades. Este es el caso del ejemplar encontrado en Bellús (Xàtiva, Valencia) datado en 1518 y estudiado recientemente por Xavier Casassas Canals que contiene un importante número de glosas y comentarios marginales en catalán, castellano y latín y que aporta asimismo nuevos datos sobre el estudio del islam entre los orientalistas de la época (Casassas Canals, Xavier. "El Alcorán de Bellús: un Alcorán mudéjar de principios del siglo XVI con traducciones y comentarios en catalán, castellano y latín." Alhadra 1 (2015): 155-177). A esto hay que añadir los ejemplares del texto sagrado ya existentes copiados en épocas anteriores y preservados durante siglos por sus comunidades, como el Corán del siglo trece hallado en Cútar (véase arriba, 3.1.3). Además de copiarlo, los musulmanes también tradujeron el Corán y sus comentarios (tafsīr) a las lenguas romances y lo hicieron no solamente con el uso de caracteres árabes sino también latinos. El Corán de Toledo es el único Corán en caracteres latinos que se ha preservado íntegro y de él disponemos ahora de una magnífica edición y de algunos trabajos adicionales sobre texto (López-Morillas, Consuelo (ed.) El Corán de Toledo: edición y estudio del manuscrito 235 de la Biblioteca de Castilla-La Mancha. Gijón: Ediciones Trea, 2011; Tottoli, Roberto. "The Toledo Qur'ān and Islamic Eschatology: Translating the Names of Hell in Aljamiado Literature." Al-Qantara: Revista de Estudios Árabes 35, No. 2 (2014): 527-553).

La literatura religiosa forma junto al Corán el grueso de la producción escrita de los mudéjares. Esta literatura ha sido tratada en extenso en el imprescindible monográfico de Luce López-Baralt que se centra en el corpus morisco para arrojar luz sobre textos que en muchos casos se remontan a originales que datan del periodo mudéjar (López-Baralt, Luce. La literatura secreta de los últimos musulmanes de España. Madrid: Trotta, 2009). Por otro lado, encontramos algunos monográficos dedicados a narraciones específicas, algunas de las cuales aúnan la escatología con la ficción al estilo de las Mil y una noches y el relato de viaje. Algunas de estas na- 
rraciones son de interés para el estudio de la literatura de polémica religiosa de la que nos ocuparemos en el apartado siguiente; este es el caso de una de las historias de los profetas, o qișaș al-anbiyā, que cuenta el viaje del judío converso al islam, Buluqiya (López-Baralt, Luce (ed.) El viaje maravilloso de Buluqiya a los confines del universo: edición, traducción, estudio introductiorio y notas de L. López-Baralt. Madrid: Trotta, 2004) y de la obra de Abū al-Hasan al-Bakrī (segunda mitad del s. XIII). sobre la vida de Muḥammad, el Kitāb al-Anwār (o Libro de las luces), recientemente editado por María Luisa Lugo de Acevedo (Lugo de Acevedo, María Luisa (ed.) El libro de las luces: leyenda aljamiada sobre la genealogía de Mahoma. Estudio y edición critica. Madrid: Sial, 2008). Sobre narrativas religiosas, consúltense también las diferentes publicaciones sobre el manuscrito de Ocaña (Hofman Vannus, Iris. "Historias religiosas musulmanas en el manuscrito mudéjar-morisco de Ocaña." PhD diss., Universidad Complutense de Madrid, 2001 y de la misma autora "El manuscrito mudéjar-morisco de Ocaña." Anaquel de Estudios Árabes 14 (2003): 119127; ibid. "El trono (de Dios), en el manuscrito mudéjar-morisco de Ocaña." 'Ilu. Revista de ciencias de las religiones 9 (2004), 91-100 y ibid. "Jesús y la calavera en el manuscrito mudéjar-morisco de Ocaña." Crónicas de Azahar: Revista de actualidad cultural del Instituto Egipcio de Estudios Islámicos en Madrid 2 (2004): 6-16. Véase también Celia del Moral, "Magia y superstición en los manuscritos de Ocaña (Toledo). Siglos XIV-XV." En Fodor, Alexander (ed.) Proceedings of the 20th Congress of the UEAI. (Budapest, 10-17 September 2000: Part Two). Budapest: Csoma de Körös Society. Section of Islamic Studies/Eötvös Loránd University. Chair for Arabic Studies, 2003, pp. 109-121).

La investigación de la literatura religiosa se ha visto estimulada por el descubrimiento de nuevos manuscritos mudéjares como los de Cútar (3.1.3) y previamente no identificados como la copia árabe hasta ahora desconocida de una de las obras del sufí de Málaga del siglo XIV, al-Sāhịīi (678/1279-754/1353), cuya edición pronto verá la luz de la mano de Mohanad Amer Khadim. La copia fue realizada por un mudéjar en Urrea de Jalón (Zaragoza) en 1510 y Amer Khadim ha demostrado que las glosas aljamiadas en los márgenes se corresponden con el texto de la copia también aljamiada en uno de los manuscritos en el Colegio Padres Escolapios de Zaragoza (manuscrito D) (Amer Khadim, Mohanad. "El día del judiçio": textos aljamiado-moriscos sobre el Juicio Final (ediciones, estudios y vocabulario)." PhD diss., 3 Vols., Departamento de Filología Española de la Universidad de Oviedo, 2017. El autor ha resumido parte de su tesis en dos artículos: "El Ġarā'ib al-nuhab fī raġā'ib al-shu 'ab, de al-Sahilīi (1279-1353), un unicum tenido por perdido (a la par que fuente de algunos capítulos del ms. Aljamiado 'D' de Zaragoza)." En Pocklington, Robert (ed.) Actas de los Simposios de la Sociedad Española de Estudios Árabes II (Almería 2015-Toledo 2016). Almería: Sociedad Española de Estudios Árabes, 2017, pp. 203-242 y "El Garā'ib al-nuhab fī rag̀ā'ib al-shu 'ab (un unicum de la Biblioteca Angelica)." En Divizia, Paolo-Pericoli, Lisa (eds.) Il viaggio del testo: Atti del Convegno internazionale di Filologia italiana e romanza (Brno, 19-21 giugno 2014). Alessandria: Edizioni dell'Orso, 2017, pp. 359-375. Dentro de esta última publicación véase también Busto Cortina, Juan Carlos. "El ms. Or. 88 de la Biblioteca Angelica y los manuscritos árabes traídos desde España por el cardenal Camillo Massimo," pp. 377-393. El estudio cuidadoso de estos materiales enriquecerá sin duda nuestros conocimientos sobre sufismo entre los mudéjares y moriscos (consúltese para los últimos la publicación de Casassas Canals, Xavier. "Devoción y sufismo en 
los manuscritos aljamiado-moriscos." En González Costa, Amina-López Anguita, María Gracia (eds.) Historia del sufismo en al-Andalus. Córdoba: Almuzara, 2009, pp. 207-237).

La oratoria como práctica y como institución social en el mundo musulmán medieval ha sido tratada brillantemente por Linda G. Jones. Su estudio subraya la importancia del sermón como mecanismo de cohesión de la comunidad musulmana (y, por lo tanto, también la de las aljamas mudéjares) y de enseñanza y aprendizaje del islam (Jones, Linda G. The Power of Oratory in the Medieval Muslim World. Cambridge: Cambridge University Press, 2012 y coordinado por la misma autora el número monográfico en Anuario de Estudios Medievales 42, No. 1 (2012) [La predicación medieval: sermones cristianos, judios e islámicos en el Mediterráneo]). Estos estudios desarrollan líneas propuestas por investigadores como María Jesús Viguera Molins y mantienen una estrecha conexión con el estudio de la plegaria, un estudio que ha ganado algo de visibilidad dentro de la disciplina (Viguera Molins, María Jesús. "Sermones aljamiados." Revista de Filología de la Universidad de La Laguna 17 (1999): 759-764); Cervera Fras, María José. "Notas sobre la rogativa en el islam mudéjar." Aragón en la Edad Media 14-15, No. 1 (1999): 291-302 y Casassas Canals, Xavier. Los siete alhaicales y otras plegarias de mudéjares y moriscos. Córdoba: Almuzara ed., 2007).

\subsubsection{Polémica interreligiosa y conversión}

El corpus literario de polémica religiosa de los mudéjares con los cristianos y con los judíos ha mostrado ser una fuente de primera importancia para entender la identidad musulmana de las comunidades mudéjares. Entre los esfuerzos principales de los investigadores de la polémica, entre los que me incluyo, ha sido el incorporar nuevos hallazgos de manuscritos al corpus existente, hacer una revisión del estado de la cuestión y de las fuentes clasificadas como moriscas por estudios previos como los de Louis Cardaillac (Cardaillac, Louis. Morisques et chrétiens: un affrontement polémique (1492-1640). Paris: Klincksieck, 1977) y mostrar que la polémica no es solo un ataque al oponente religioso, sino que constituye un mecanismo central en la construcción y articulación de discursos de la identidad que se adaptan a las necesidades de los contextos históricos y sociales en que vivían los mudéjares (Colominas Aparicio, Mònica. The Religious Polemics of the Muslims of Late Medieval Iberia. Identity and Religious Authority in Mudejar Islam [The Medieval and Early Modern Iberian World 64]. Leiden, Boston: Brill, 2018; también "Disputes about Purity in Late Medieval Iberia. Interreligious Contacts and the Polemical Language of the Mudejars." Journal of Transcultural Medieval Studies 1, No. 1 (2014): 117-141 y ibid. "Disputa con los cristianos [MS BNE 4944, Aljamiado XVI (or XVII) century]." En Thomas, David-Chesworth, John (eds.) Christian-Muslim Relations: A Bibliographical History. Vol. 6. Western Europe (1500-1600). Leiden, Boston: Brill, 2014, pp. 43-48).

Trabajos como los de Gerard Wiegers muestran que esta literatura nos permite adentrarnos en cuestiones sobre la permanencia del islam mudéjar en los territorios y en su aportación al corpus morisco, por ejemplo, a partir del uso de fuentes cristianas para la composición de profecías con fines polémicos (Wiegers, Gerard Albert. "Jean de Roquetaillade's Prophecies Among the Muslim Minorities of Medieval and Early-Modern Christian Spain: An Islamic Version of the Vademecum in Tribulatio- 
ne." En Boekhoff-van der Voort, Nicolet-Versteegh, Kees-Wagemakers, Joas (eds.) The Transmission and Dynamics of the Textual Sources of Islam: Essays in Honour of Harald Motzki. Leiden: Brill, 2011, pp. 229-247). Del mismo modo hay que destacar los estudios de Mercedes García-Arenal y Katarzyna K. Starczewska sobre mudéjares conversos al cristianismo (las autoras son capaces de identificar y esbozar la biografía de la figura del converso Juan Gabriel) y su papel en la transmisión de conocimiento de polémica islamo-cristiana (García-Arenal, Mercedes-Starczewska, Katarzyna K. "The Law of Abraham the Catholic: Juan Gabriel as Qur'ān Translator for Martín de Figuerola and Egidio da Viterbo." Al-Qanțara: Revista de Estudios Árabes 35, No. 2 (2014): 409-459 y Katarzyna Starczewska. "Juan Gabriel of Teruel." En Thomas, David-Chesworth, John (eds.) Christian-Muslim Relations: A Bibliographical History. Volume 6. Western Europe (1500-1600). Leiden, Boston: Brill, 2014, pp. 415-419). Finalmente, se deben de señalar dos importantes trabajos editados por Mercedes García-Arenal y Gerard Wiegers: Polemical Encounters: Christian, Jews and Muslims in Iberia. Philadelphia, Pennsylvania: University of Pennsylvania Press (in press) y el número monográfico en la revista Medieval Encounters 24 (2018) [Interreligious Encounters in Polemics between Christians, Jews, and Muslims in Iberia and Beyond] con contribuciones sobre musulmanes en los territorios cristianos como las de Eleazar Gutwirth y Ana Echevarría Arsuaga.

La conversión de musulmanes en la época medieval, moderna y contemporánea es el tema bajo el que se reúnen las diversas contribuciones al magnífico volumen dirigido por Mercedes García-Arenal (Conversions islamiques: identités religieuses en islam méditerranéen/Islamic Conversions: Religious Identities in Mediterranean Islam. Paris: Maisonneuve et Larose, 2001). Disponemos también de tres volúmenes aparecidos en Brill entre 2009 y 2015 y editados por Kevin Ingram (el tercer volumen, lo edita junto con Juan Ignacio Pulido Serrano), con trabajos de relevancia para el estudio de los mudéjares en el primer volumen (Ingram, Kevin (ed.) Conversos and Moriscos in Late Medieval Spain and Beyond). Ha habido además dos publicaciones con visiones clave para el tema de la conversión, por un lado, el artículo de David Nirenberg ("Mass Conversion and Genealogical Mentalities: Jews and Christians in Fifteenth-Century Spain." Past and Present 174, No. 1 (2002): 3-41) y, por el otro, la monografía de Ryan Szpiech en la que la conversión entre judaísmo y cristiandad ocupa un papel central (Szpiech, Ryan. Conversion and Narrative: Reading and Religious Authority in Medieval Spain. Philadelphia: University of Pennsylvania Press, 2013). Véase también sobre conversión el sólido volumen editado por Mercedes García-Arenal (After Conversion. Iberia and the Emergence of Modernity. Leiden, Boston: Brill, 2016) y algunas de sus interesantes contribuciones sobre conversos como las de Teresa Soto González y Katarzyna K. Starczewska (Soto González, Teresa-Starczewska, Katarzyna K. "Authority, Philology and Conversion under the Aegis of Martín García") y Ryan Szpiech (Szpiech, Ryan. "A Witness of Their Own Nation: On the Influence of Juan Andrés").

Cabe observar, sin embargo, que las conversiones de los mudéjares han recibido una atención moderada en el nuevo milenio (aquí destacamos los artículos de Molénat, Jean-Pierre. "En los últimos años del siglo XV: el fin de los "mudéjares viejos" de Castilla." En García de Cortázar, José Ángel et al. Fines de siglo y milenarismo en la historia. Valladolid: Instituto Universitario Historia Simancas, Universidad de Valladolid, 2001, pp. 31-56; Martín Padilla, Encarnación. "Notas sobre la relación de moros de la aljama de Zaragoza y conversos de su comunidad (siglo XV)." Al- 
Qantara: Revista de estudios árabes 24, No. 1 (2003): 169-178; Rufo Ysern, Paulina. "La conversión de la comunidad musulmana de Écija." En García Sanjuán, Alejandro (coord.) Tolerancia y convivencia étnico-religiosa en la Península Ibérica durante la Edad Media: III Jornadas de Cultura Islámica. Huelva: Universidad de Huelva, 2003, pp. 151-197 y Galán Sánchez, Ángel. "De mudéjares a moriscos: los problemas metodológicos de una transición." En Barrios Aguilera, Manuel-Galán Sánchez, Ángel (coord.) La historia del reino de Granada a debate: viejos y nuevos temas. Perspectivas de estudio. Málaga: Editorial Actas, 2004, pp. 303-328.

\subsection{Transmisión del conocimiento: lenguaje, producción manuscrita y codicología}

Hay una preferencia por el estudio de las prácticas lingüísticas y de la producción manuscrita de los moriscos frente a la de los mudéjares que se observa tanto en los estudios sobre codicología como en la investigación de las prácticas de escritura. Los moriscos ocupan un lugar central en el estudio del lenguaje y en importantes publicaciones como el volumen editado sobre aljamía, no solo entre musulmanes sino también entre judíos, a cargo de Raquel Suárez García e Ignacio Ceballos Viro mientras que las escasas publicaciones que tratan el periodo mudéjar se ocupan de estas prácticas junto con las de los moriscos:

- Casassas Canals, Xavier. "La literatura aljamiado-morisca en el marco de la literatura islámica española: siglos XIII-XVII (Una variedad del castellano vinculada al hiero-Sprachbundislámico)." En Benlabbah, Fatiha-Chalkha, Achouak (coord.) Los moriscos y su legado desde ésta y otras laderas. Rabat: Instituto de Estudios Hispano-Lusos, 2010, pp. 368-396.

- Ferrando, Ignacio. "Andalusi Arabic in Post-Islamic North of Spain: The Language of Aragon's Mudejars and Moriscos." En Mifsud, Manwell (ed.) Proceedings of the Third International Conference of the Association Internationale de Dialectologie Arabe. Malta: Salesian Press, 2000, pp. 195-200.

- Galmés de Fuentes, Álvaro-Temimi, Abdeljelil (eds.) Mu'assasat al-Tamīmī li-lbahth al- 'ilmī wa-l-ma 'lūmàt. Hommage à l'école d'Oviedo d'études aljamiado: dédié au fondateur Álvaro Galmés de Fuentes. Zaghouan: Fondation Temini pour la Recherche Scientifique et l'Information, 2003.

- Suárez García, Raquel-Ceballos Viro, Ignacio (coord.) Aljamías: in memoriam Álvaro Galmés de Fuentes y Iacob M. Hassán. Gijón: Trea, 2012.

Es del conocimiento de la presente autora que el próximo volumen de Brill editado por Heather Bamford y Alberto Montaner (Bamford, Heather-Montaner, Alberto (eds.) A Companion to Aljamiado Literature) incluye contribuciones sobre la producción escrita e intelectual mudéjar. Debemos también mencionar los dos artículos de publicación inminente de Nuria de Castilla y de Mònica Colominas Aparicio, ambos sobre producción aljamiada, cultura e identidad de sus comunidades (Intellectual History of Islamicate World, 2019) y otra futura publicación para Sharq alAndalus de catalogación de los manuscritos aljamiados de las Escuelas Pías de Zaragoza a cargo de Olivier Brisville-Fertin.

Por el momento entre las aportaciones más interesantes sobre la producción y transmisión de conocimiento entre los mudéjares contamos con el reciente estudio 
de los hallazgos de Cútar por Calero Secall, María Isabel et al. (véase arriba, 3.1.3) y con el artículo sobre las bibliotecas de dos alfaquíes de Borja (Aragón) en 1526 antes de su conversión al cristianismo, así como la aportación de Jorge Pascual Asensi sobre la circulación de ideas y fuentes musulmanas de Oriente a Occidente (Labarta Gómez, Ana-Escribano, Carlos. "Las bibliotecas de dos alfaquíes borjanos." Anaquel de Estudios Árabes 11 (2000): 355-367; Pascual Asensi, Jorge. "Las "demandas" de los diez sabios judíos al profeta Mahoma. Un rastro de la sīra de Ibn Ishạa en la literatura de mudéjares y moriscos." En Actas del XI Simposio Internacional de Mudejarismo: Teruel, 18-20 de septiembre de 2008. Teruel: Centro de Estudios Mudéjares, 2009, pp. 871-886).

\subsection{Minorías dentro de las minorías: mujeres y esclavos}

En último lugar, aunque no por ello menos interesante se encuentra el estudio de las mujeres y de los esclavos, es decir, de unos grupos minoritarios dentro de las minorías mudéjares. Mientras que hay pocas publicaciones sobre la esclavitud mudéjar, las mujeres parecen haber despertado un mayor interés (consúltense para los esclavos Ruzafa García, Manuel. "La esclavitud en la Valencia bajomedieval: mudéjares y musulmanes.” En Ferrer i Mallol, Maria Teresa-Mutgé i Vives, Josefa (eds.) De la esclavitud a la llibertat: esclaus i lliberts a l'edat mitjana, actes del col-loqui internacional celebrat a Barcelona, del 27 al 29 de maig de 1999. Barcelona: Consell Superior d'Investigacions Científiques, 2000, pp. 471-491; Echevarría Arsuaga, Ana. "La "mayoría" mudéjar en León y Castilla: legislación real y distribución de la población (siglos XI-XIII).” En la España Medieval 29 (2007): 7-30; Marzal Palacios, Francisco Javier. "Minorías en la España medieval (I): esclavos, mudéjares y moriscos." eHumanista 10 (2008): 293-252).

Algunas publicaciones de interés como la monografía de Emma María Guijarro Hortelano aportan interesantes datos sobre la maternidad y la implicación de la mujer en el conocimiento y práctica de la medicina mientras que otras arrojan luz sobre los ideales de mujer en fuentes literarias (Guijarro Hortelano, Emma María. La maternidad en las comunidades mudéjar y morisca según un manuscrito aljamiadomorisco aragonés. Teruel: Centro de Estudios Mudéjares, 2010; Hofman Vannus, Iris. "Mujeres mudéjares. Ideales de mujer reflejados en el manuscrito mudéjarmorisco de Ocaña." Encuentro islamo-cristiano 416 (2006): 1-15 y de la misma autora "Mujeres mudéjares en la España medieval." Hespéria. Culturas del Mediterráneo 4 (2006): 279-289). La contribución de Carmen Díaz de Rábago Hernández se añade aquí y trata un tema bastante desconocido, a saber, el papel de las mujeres mudéjares en el ámbito económico (Díaz de Rábago Hernández, Carmen. "Mujeres mudéjares en operaciones económicas durante del siglo XV valenciano: el papel de la dote islámica." En Actas del VII Simposio Internacional de Mudejarismo: Teruel, 19-21 de septiembre de 1996. Teruel: Centro de Estudios Mudéjares, Instituto de Estudios Turolenses, 1999, pp. 55-64).

\section{El estado de la cuestión sobre los estudios mudéjares}

Los trabajos que hemos comentado permiten dibujar de forma aproximada los contornos de las líneas de investigación reciente sobre los mudéjares. Me gustaría cerrar 
la presente bibliografía con unas breves reflexiones y con unas referencias bibliográficas sobre el estado de la cuestión.

A modo de consideración general y retomando lo que ya se ha señalado en la introducción, podemos decir que los estudios mudéjares en el siglo veintiuno se entienden por un lado en estrecho diálogo con el debate actual sobre la integración de minorías religiosas y por el otro con los movimientos dentro de la academia que reaccionan a los postulados positivistas y de la modernidad y que se movilizan de forma heterogénea, aunque consistentemente por oposición al periodo anterior (por lo que a menudo se denominan con el prefijo "post" -colonial, -moderno, -estructuralista). Solo teniendo en cuenta estos dos elementos es posible entender la vitalidad de los debates en torno a la convivencia en la literatura, así como el cambio en las perspectivas tomadas para el estudio de las prácticas de los mudéjares y de los moriscos.

De este modo, se ha señalado la gran atención dirigida hacia el estudio del islam de los musulmanes en territorio cristiano y el hecho de que tanto su práctica como la historia de sus comunidades haya dejado de entenderse exclusivamente en términos de decadencia y se haya subrayado la participación activa de sus miembros en la articulación de discursos propios de la identidad, algo que en la literatura del mundo anglosajón se conoce por "agency". Las redes entre individuos y aljamas dentro y fuera de la península Ibérica han mostrado tener una importancia clave para entender el fenómeno mudéjar y su estudio ha llevado a los investigadores a realizar esfuerzos por explorar nuevas vías y por cuestionar una serie de categorías ya establecidas. Hay una clara evidencia de que hubo intensas relaciones entre los mudéjares de Castilla con los de Aragón, así como de que se produjo una circulación y copia de manuscritos y se usaron fuentes árabes hasta fechas tardías, pero faltan aún estudios de comparación detallados que sean capaces de integrar a estas comunidades (y por extensión a las comunidades en los diferentes reinos cristianos) dentro de marcos de comprensión coherentes. Por otro lado, las colaboraciones entre disciplinas han demostrado tener el potencial de abrir prometedoras perspectivas para el estudio de los mudéjares, pero hasta ahora estas iniciativas no se han llevado a cabo con la regularidad necesaria para producir cambios estructurales en la metodología y epistemología de la disciplina.

Para concluir podemos decir que, construyendo sobre los importantes hitos alcanzados en el periodo previo, la investigación sobre los mudéjares en el siglo veintiuno ha sabido poner de relieve los aspectos más genuinos e interesantes de las condiciones de vida de unas comunidades de musulmanes libres que vivían en minoría, de tal forma que los estudios sobre estas comunidades son actualmente una disciplina atractiva no solamente para quienes se ocupan de cuestiones sobre la península ibérica o el periodo pre-moderno sino también para los estudiantes de leyes, de antropología y de religión. La visibilidad alcanzada por los estudios mudéjares y la mayor definición de las bases sobre las que se asienta la disciplina revelan el sesgo provocado por acercamientos que de forma acrítica se habían ocupado de sus minorías junto con las de los moriscos. La presente autora es del parecer que el reconocimiento de la posición diferenciada de los mudéjares es un paso indispensable para poder evaluar la transición entre sus comunidades y las de los moriscos, una transición resultante de un cambio de condición jurídica que no necesariamente arraigó en las bases de las comunidades mudéjares y que sugiere que en lugar de ruptura entre los periodos mudéjar y morisco debamos quizás hablar de diferentes grados y formas de continuidad. 
- Actas del X Simposio Internacional de Mudejarismo: 30 años de Mudejarismo, memoria y futuro [1975-2005]. Teruel 14-16 septiembre de 2005. Teruel: Centro de Estudios Mudéjares, Instituto de Estudios Turolenses, 2007.

- Burns, Robert I. "Mudejar Parallel Societies: Anglophone Historiography and Spanish Context 1975-2000." En Meyerson, Mark. D.-English, Edward D. (eds.) Christians, Muslims, and Jews in Medieval and Early Modern Spain. Interaction and Cultural Change. Notre Dame [Ind.]: University of Notre Dame Press, 2000; 91-124.

- Colominas Aparicio, Mònica-Wiegers, Gerard Albert. "The Religion of the Muslims of Medieval and Early Modern Castile: Interdisciplinary Research and Recent Studies on Mudejar Islam (2000-2014)." Edad Media: Revista de Historia [Volumen monográfico Islam en minoría en la Edad Media] 17 (2016): 97-108.

- Echevarría Arsuaga, Ana. "Los mudéjares de los reinos de Castilla y Portugal." Revista d'Història Medieval 12 (2001-2002): 31-46.

- Echevarría Arsuaga, Ana. "Los mudéjares: ¿minoría, marginados o grupos culturales privilegiados?" Medievalismo. Revista de la Sociedad Española de Estudios Medievales 18 (2008): 45-65.

— Ladero Quesada, Miguel Ángel. "Los mudéjares de Castilla cuarenta años después." En la España Medieval 33 (2010): 383-424.

— Molénat, Jean-Pierre. "Douze années d'études mudéjares (2001-2013)." Hamsa. Journal of Judaic and Islamic Studies 1 (2014): 41-54.

- Nirenberg, David. "Muslims in Christian Iberia, 1000-1526: Varieties of Mudejar Experience." En Linehan, Peter-Nelson, Janet L. (eds.) The Medieval World. London, New York: Routledge, 2001, pp. 60-76.

\section{Anexo: trabajos sobre mudejarismo en el arte y la arquitectura}

Junto con las monografías y volúmenes editados que se señalan a continuación, se sugiere al lector interesado la consulta de las Actas de los Simposios Internacionales de Mudejarismo (Centro de Estudios Mudéjares de Teruel), en particular Actas IX que incluye la contribución de Ana Reyes Pacios Lozano (Pacios Lozano, Ana Reyes. "Diez años de bibliografía sobre el arte mudéjar (1992-2002)." En Actas del IX Simposio Internacional de Mudejarismo: Mudéjares y moriscos, cambios sociales y culturales. Teruel: Centro de Estudios Mudéjares, Instituto de Estudios Turolenses, 2004, pp. 285-298), así como también Actas XI (2009) y XII (2013). Consúltense también el volumen coordinado por Jesús Fermín Criado Mainar (Criado Mainar, Jesús Fermín (coord.) Arte mudéjar aragonés: patrimonio de la Humanidad. Actas del X Coloquio de Arte de Aragón. Zaragoza: Institución "Fernando el Católico", 2002) y las actas del X Curso de la Cátedra "Goya" sobre arte mudéjar en 2005 coordinado por María del Carmen Lacarra Ducay (Lacarra Ducay, María del Carmen (coord.) Arte mudéjar en Aragón, León, Castilla, Extremadura y Andalucía. Zaragoza: Institución "Fernando el Católico", 2006). Finalmente, contamos con la publicación del catálogo de la exposición de manuscritos con encuadernación mudéjar de la biblioteca real de Alfonso el Magnánimo que se preservan en la Universidad de Valencia editado por María Isabel Álvaro Zamora, María Luz Mandingorra Llavata y Donatella Giansante (Álvaro Zamora, María Isabel-Mandingorra Llavata, María Luz-Giansante, Donatella (eds.) Els vestits del saber: enquadernacions mudèjars a 
la Universitat de València. València: Universitat de València, 2003). Otra aportación que cabe señalar es el volumen editado por Gonzalo M. Borrás Gualis en el que se recogen facsímiles de artículos clásicos en la historiografía del mudejarismo hoy de difícil acceso (Borrás Gualis, Gonzalo M. (ed.) Estudios de arte mudéjar aragonés. Zaragoza: Institución "Fernando el Católico", 2002).

- Alcalá Prats, Iciar-Revilla Hernando, Ana María-Rodrigo Garza, Beatriz. Guía del arte mudéjar en Aragón. Teruel: Centro de Estudios Mudéjares, 2005.

- Biel Ibáñez, María Pilar-Hernández Martínez, Ascensión. La arquitectura neomudéjar en Aragón. Zaragoza: Rolde de Estudios Aragoneses, Institución "Fernando el Católico", 2005.

- Borrás Gualis, Gonzalo M. (dir.) Tierra mudéjar: el Mudéjar Aragonés, Patrimonio de la Humanidad. Zaragoza: Heraldo de Aragón, 2002.

- Cabañero Subiza, Bernabé. La techumbre mudéjar de la sala capitular del Monasterio de Sijena: la techumbre mudéjar de la sala capitular del Monasterio de Sijena. Tarazona: Instituto de Estudios Turiasonenses, 2000.

- Cortés Martínez, Inmaculada (coord.) Síntesis de culturas, mudéjar: itinerario cultural del mudéjar en México. Granada: Fundación "El Legado Andalusí", 2002.

- Duque Herrero, Carlos-Regueras Grande, Fernando-Sánchez del Barrio, Antonio. Rutas del mudéjar en la provincia de Valladolid. Valladolid: Castilla Ediciones, 2006.

— Gutiérrez Robledo, José Luis. Sobre el mudéjar en la provincia de Ávila. Ávila: Instituto de Arquitectos Juan de Herrera, 2001.

- Iglesias Picazo, Pedro. El islam en tierras cristianas: los mudéjares. Restauración de la Ermita Santa María La Antigua de Carabanchel. Madrid: Doce Calles, 2003.

— Jiménez Esteban, Jorge. El mudéjar madrileño. Madrid: Ediciones La Librería, 2001.

- Jordano Barbudo, María Ángeles. El mudéjar en Córdoba. Córdoba: Diputación de Córdoba, 2002.

- López Guzmán, Rafael. Arquitectura mudéjar: del sincretismo medieval a las alternativas hispanoamericanas. Madrid: Cátedra, 2000.

- López Fernández, María Isabel. La arquitectura mudéjar en Ávila. Ávila: Diputación Provincial, 2004.

- Noufouri, Hamurabi-Martínez Nespral, Fernando. Nociones de estética arábiga y mudéjar: conceptos generales y pautas referenciales sobre el arte y el diseño del mundo islámico del Mediterráneo. Buenos Aires: Ed. Cálamo, 1999.

- Pacios Lozano, Ana Reyes. Bibliografía de arte mudéjar: Addenda. 1992-2002. Teruel: Centro de Estudios Mudéjares, 2002.

- Pardo Fernández, María Antonia (ed.) La recuperación del patrimonio arquitectónico mudéjar en la provincia de Badajoz: 1990-1998. Cáceres: Universidad de Extremadura, 2004. 
